\title{
Adherence to guidelines on prophylaxis of chemotherapy-induced nausea and vomiting in the National Cancer Institute, Sudan
}

\begin{tabular}{|c|c|}
\hline \multicolumn{2}{|c|}{$\begin{array}{l}\text { Authors: } \\
\text { Moawia M.A. Elhassan }{ }^{1} \text { (D) } \\
\text { Arwa A.S.A. Ali }{ }^{2} \\
\text { Mohamed O.M. Elmustafa }^{3}\end{array}$} \\
\hline \multicolumn{2}{|c|}{$\begin{array}{l}\text { Affiliations: } \\
{ }^{1} \text { National Cancer Institute, } \\
\text { University of Gezira, Sudan }\end{array}$} \\
\hline \multicolumn{2}{|c|}{$\begin{array}{l}{ }^{2} \text { Wad Medani Teaching } \\
\text { Hospital, Sudan }\end{array}$} \\
\hline \multicolumn{2}{|c|}{$\begin{array}{l}{ }^{3} \text { Faculty of Pharmacy, } \\
\text { University of Gezira, Sudan }\end{array}$} \\
\hline \multicolumn{2}{|c|}{$\begin{array}{l}\text { Corresponding author: } \\
\text { Moawia Elhassan, } \\
\text { moawia2@gmail.com }\end{array}$} \\
\hline \multicolumn{2}{|c|}{$\begin{array}{l}\text { Received: } 12 \text { Jan. } 2016 \\
\text { Accepted: } 06 \text { Feb. } 2016 \\
\text { Published: } 28 \text { Feb. } 2017\end{array}$} \\
\hline \multicolumn{2}{|c|}{$\begin{array}{l}\text { How to cite this article: } \\
\text { Elhassan MMA, Ali AASA, } \\
\text { Elmustafa MOM. Adherence } \\
\text { to guidelines on prophylaxis } \\
\text { of chemotherapy-induced } \\
\text { nausea and vomiting in the } \\
\text { National Cancer Institute, } \\
\text { Sudan. S. Afr. j. oncol. } \\
2017 ; 1(0) \text {, a9. https://doi. } \\
\text { org/10.4102/sajo.v1i0.9 }\end{array}$} \\
\hline \multicolumn{2}{|c|}{$\begin{array}{l}\text { Copyright: } \\
\text { (C) 2017. The Authors. } \\
\text { Licensee: AOSIS. This } \\
\text { is licensed under the } \\
\text { Creative Commons } \\
\text { Attribution License. }\end{array}$} \\
\hline \multicolumn{2}{|l|}{ Read online: } \\
\hline 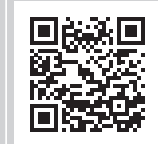 & $\begin{array}{l}\text { Scan this QR } \\
\text { code with your } \\
\text { smart phone or } \\
\text { mobile device } \\
\text { to read online. }\end{array}$ \\
\hline
\end{tabular}

Objective: To evaluate the adherence to American Society of Clinical Oncology (ASCO) guidelines for antiemetic prophylaxis of chemotherapy-induced nausea and vomiting and assess the outcomes of the prescribed antiemetic drugs.

Methods: This prospective, observational study enrolled chemotherapy-naive cancer patients who were admitted to the National Cancer Institute between May and July 2015 for intravenous chemotherapy. Patient's demographic data, chemotherapy protocols and types of antiemetic drugs were collected by reviewing patients' files, chemotherapy prescription forms and interviewing the patients.

Results: The data revealed that $90 \%$ of pre-chemotherapy antiemetic prescriptions did not adhere to antiemetic guidelines. The trends of non-adherence included an overuse of ondansetron (14\%), under-prescribing of dexamethasone (16\%) and corticosteroid duplication $(14 \%)$. Regarding antiemetic use for the prevention of delayed emesis, the data showed that $90 \%$ of antiemetic prescriptions were non-adherent with ASCO guidelines, with overuse of ondansetron (20\%) and metoclopramide (37\%) and lack of dexamethasone prescriptions (80\%) on days 2 and 3 being the most frequently reported trends. The percentage of patients with complete response (no emesis or rescue therapy) over 5 days post chemotherapy was $36 \%$.

Conclusion: The study indicated an extremely low adherence rate to ASCO guidelines for antiemetic prophylaxis of chemotherapy-induced nausea and vomiting. Non-adherence included a trend of both underuse and overuse of indicated antiemetic medications.

\section{Introduction}

Chemotherapy is the cornerstone in the management of different malignant disorders. Anticancer drugs have a narrow therapeutic index and are known to cause significant acute and delayed adverse drug reactions. ${ }^{1}$ Chemotherapy-induced nausea and vomiting (CINV) is a serious side effect that can impact quality of life (QOL) and impair patients' adherence to treatment. ${ }^{2}$ The intrinsic emetogenicity of the chemotherapeutic agents is the most important factor determining the likelihood of development of acute or delayed emesis during chemotherapy., ${ }^{3,4}$ In fact, all chemotherapeutic agents have emetogenic potential of different intensities and accordingly are classified into four emetic risk groups depending on the percentage of cases they cause emesis in: high $(>90 \%)$, moderate $(30 \%-90 \%)$, low $(10 \%-30 \%)$ and minimal $(<10 \%){ }^{5}$

Three distinct forms of CINV can be distinguished depending on the time at which emesis occurs after initiation of treatment. These are acute emesis arising within $24 \mathrm{~h}$ of chemotherapy administration, delayed emesis arising after the first $24 \mathrm{~h}$ and lasting for up to 6 days, and anticipatory emesis that occurs prior to the administration of chemotherapy. ${ }^{6}$

In the absence of antiemetic prophylaxis, about $70 \%-80 \%$ of cancer patients receiving chemotherapy experience CINV. ${ }^{7}$ However, proper use of antiemetic medication has the potential to improve control of CINV, maximise patients' QOL and reduce associated symptoms' management costs. ${ }^{8,9}$ Several clinical guidelines have addressed the importance of the prophylactic administration of antiemetic drugs for preventing CINV, including the American Society of Clinical Oncology (ASCO), Multinational Association of Supportive Care in Cancer/European Society for Medical Oncology (MASCC/ESMO) and National Comprehensive Cancer Network $(\mathrm{NCCN}) .{ }^{10,11,12}$ There is constancy among these guidelines on key principles with only minor differences. ${ }^{5,13}$ Although these guidelines are widely available and regularly updated, adherence is often low. 
Although the adherence rate to antiemetic guidelines for the prevention of CINV has been studied extensively in the medical literature, there is lack of adequate information about adherence to the guidelines for antiemetic prophylaxis in cancer patients in Sudan. In this study, the adherence to ASCO guidelines for the use of antiemetic medications was studied in cancer patients who received chemotherapy at the outpatient chemotherapy unit, The National Cancer Institute (NCI), Wad Medani, Sudan.

\section{Patients and methods}

\section{Study design}

This was a prospective observational study conducted at the oncology department at the NCI, University of Gezira in central Sudan, over a 3 month period from May to July 2015.

\section{Patients}

Previously untreated patients (chemotherapy naïve) who underwent intravenous chemotherapy during the study period were eligible for inclusion in this study. Exclusion criteria were brain metastases, concurrent radiation therapy and pregnancy. In addition, patients who were on any other emetogenic drugs were excluded.

\section{Data collection}

Data extracted from patients' files included patient demographics and baseline clinical characteristics, chemotherapy protocol and prescribed antiemetic regimen. In addition, patients were followed up through telephone to answer questions about emesis events, severity of nausea and vomiting and compliance with dose instructions for antiemetic therapy for 7 days post chemotherapy administration. Day one was the day of chemotherapy and first day of antiemetic therapy. Chemotherapies were classified according to their emetogenic risk as high, moderate and low or minimal according to the ASCO classification. Pharmacists and physicians working with these patients were unaware of the study to minimise the risk of bias. A pilot with 10 cases was carried out to determine if the data collection form was able to capture all the information required for data analysis. All data were collected after obtaining patient consent and were analysed anonymously without identifying patient information.

\section{Statistical analyses}

Data were analysed using the Statistical Package for Social Sciences for Windows (SPSS II; ver. 20 SPSS Inc., Chicago, IL, USA). Descriptive statistical analysis was carried out; the results were presented as frequencies and percentages.

\section{Results}

A total of 100 cancer patients met the inclusion criteria. The mean age was 26.06 years. The majority of the study population were female patients $(n=63)$ representing $63 \%$, whilst male patients were $37(37 \%)$ cases. There were 12 paediatric patients $(<16$ years old), representing $12 \%$ of the total study population. The performance status of all participants was either I or II according to the Eastern Cooperative Oncology Group. Breast cancer was the most common diagnosis followed by non-Hodgkin's lymphoma (NHL). Patient characteristics and tumour sites are shown in Table 1.

The majority of chemotherapy prescriptions were classified as high emetic risk chemotherapy (HEC) regimens. The most frequent regimens were an anthracycline plus cyclophosphamide (52\%), followed by cisplatin-based regimens (21\%). The distribution of chemotherapy according to their emetogenic potential is shown in Table 2.

The data showed that $90 \%$ of pre-chemotherapy antiemetic prescriptions did not adhere to ASCO guidelines. The trends of non-adherence included an overuse of ondansetron (5-HT3 receptor antagonist) in 2 and 12 patients treated with minimal emetic risk chemotherapy (MinEC) and low emetic risk chemotherapy (LEC), respectively. There was also a trend of under-prescribing of dexamethasone for 16 patients receiving HEC and moderate emetic risk chemotherapy (MEC) regiments. Corticosteroid duplication was reported in $14 \%$ of patients. None of the patients who were on HEC received NK 1 receptor antagonists because of unavailability of this treatment choice in our facility.

TABLE 1: Patient characteristics $(N=100)$.

\begin{tabular}{ll}
\hline Characteristics & $\%$ \\
\hline Sex & 37 \\
Male & 63 \\
Female & \\
Age & 12 \\
$1-15$ & 12 \\
$16-30$ & 40 \\
$31-45$ & 23 \\
$46-60$ & 13 \\
$61-85$ & \\
Residence & 71 \\
Rural & 29 \\
Urban & \\
Diagnosis & 27 \\
Breast cancer & 14 \\
Non-Hodgkin's lymphoma (NHL) & 9 \\
Acute lymphoblastic leukaemia & 8 \\
Nasopharyngeal carcinoma & 7 \\
Acute myeloid leukaemia & 5 \\
Colon cancer & 5 \\
Cervical cancer & 10 \\
Ovarian cancer & \\
Others & \\
\hline
\end{tabular}

TABLE 2: Distribution of chemotherapy according to emetogenic potential of chemotherapeutic agents $(N=100)$.

\begin{tabular}{lc}
\hline Emetogenic potential & No. (\%) \\
\hline High & $73(73)$ \\
Moderate & $7(7)$ \\
Low & $16(16)$ \\
Minimal & $4(4)$ \\
\hline
\end{tabular}


TABLE 3: Analysis of frequently used single and combination prophylactic antiemetic regimens.

\begin{tabular}{|c|c|c|c|c|c|}
\hline Regimens & HEC & MEC & LEC & MinEC & Total \\
\hline \multicolumn{6}{|l|}{ Single antiemetic } \\
\hline Ondansetron & 5 & 1 & 3 & 2 & 11 \\
\hline \multicolumn{6}{|l|}{ Combination of two antiemetic drugs } \\
\hline Ondansetron + dexamethasone & 39 & 5 & 8 & 0 & 52 \\
\hline Ondansetron + metoclopramide & 1 & 1 & 0 & 0 & 2 \\
\hline Dexamethasone + metoclopramide & 22 & 0 & 4 & 2 & 28 \\
\hline \multicolumn{6}{|l|}{ Combination of three antiemetic drugs } \\
\hline $\begin{array}{l}\text { Ondansetron }+ \text { dexamethasone }+ \\
\text { metoclopramide }\end{array}$ & 6 & 0 & 1 & 0 & 7 \\
\hline
\end{tabular}

HEC, high emetic risk chemotherapy; MEC, emetic risk chemotherapy; LEC, low emetic risk chemotherapy; MinEC, minimal emetic risk chemotherapy.

Regarding antiemetic use for the prevention of delayed emesis, the data showed that $90 \%$ of antiemetic prescriptions were non-adherent with ASCO guidelines. Overuse of ondansetron was observed in $20 \%$ of prescriptions, lack of dexamethasone prescriptions on days 2 and 3 post chemotherapy was observed in $80 \%$ and overuse of metoclopramide was observed in $37 \%$ of prescriptions (Table 3).

The percentage of patients with complete response (no emesis or rescue therapy) over 5 days post chemotherapy was 36\%. Acute vomiting was experienced by $37 \%$ of the patients and delayed vomiting by $12 \%$, whilst acute nausea was present in $49 \%$ of the patients and delayed nausea in $14 \%$.

\section{Ethical consideration}

The study was approved by the Ethical committee at the Faculty of Medicine, University of Gezira. Subsequently, the study proposal was reviewed by the research committee of the Department of Oncology for feedback from physicians treating the potential participants. After identifying eligible patients and obtaining the consultant's agreement, verbal consent was obtained from each patient. The verbal consent explained the study aims, objectives and potential value, and all data were collected anonymously.

\section{Discussion}

The current cross-sectional prospective observational study is the first study conducted to investigate the pattern of antiemetic medications prescribed for prophylaxis of CINV, their adherence to guidelines and their efficacy in patients undergoing the first cycle of chemotherapy at NCI, Gezira State, Sudan. This observational study reflects the treatment pattern in a real practice. In Sudan, antiemetic medications used for the prevention of CINV are free of charge to Sudanese citizens at governmental institutions; therefore, medication cost and clinicians trend to prescribe treatment according to reimbursement guidelines were not considered as confounding factors influencing antiemetic prescribing pattern in our setting.

CINV are adverse events that should be totally controlled to reduce morbidity and prevent premature termination of chemotherapy. The goal of clinical guidelines is mainly focused on the complete prevention of CINV rather than on treatment. This should be achievable in the majority of patients receiving chemotherapy, even with highly emetic agents so as to improve QOL and avoid complications. Aapro et al. reported that adherence to antiemetic guidelines significantly increased the control of CINV in patients receiving highly or moderately emetogenic chemotherapy agents. ${ }^{13}$ For acute emesis, the updated ASCO guidelines recommend triple therapy with NK1-receptor antagonist (NK1-RA), a 5-HT3 receptor antagonist and dexamethasone for HEC regimens (including anthracycline plus cyclophosphamide containing regimens). For MEC regimens, the updated ASCO guidelines recommend palonosetron and dexamethasone or 5-HT3 receptor antagonist, dexamethasone and aprepitant. In low emetogenic chemotherapy, a monotherapy with dexamethasone is recommended, and for minimal emetogenic chemotherapy, no prophylaxis is necessary. ${ }^{10}$ For delayed emesis, the updated ASCO guidelines recommend in patients receiving HEC (including anthracycline plus cyclophosphamide containing regimens) a combination of a dexamethasone and NK1-RA. In other MEC regimens, 5-HT3 receptor antagonist, dexamethasone or NK1-RA is recommended. In low and minimal emetogenic chemotherapy, no prophylaxis is necessary. ${ }^{10}$

Despite the availability of treatment guidelines, there is evidence that adherence to treatment recommendations is less than optimal. ${ }^{14,15}$

Our analysis revealed that most patients received prophylactic antiemetic therapy with two drugs followed by those treated with one drug and that 5-HT3 receptor antagonists and glucocorticoids were the most widely used drugs for prophylactic antiemetic therapy. NK1-RA and palonosetron were not used as they are not registered for clinical use in our setting, and this could be a possible confounding factor for non-adherence to ASCO guidelines.

In this study, about $90 \%$ of pre-chemotherapy antiemetic prescriptions regimens did not adhere to the ASCO guidelines. Similar result has been reported in Saudi Arabia. ${ }^{16}$ Koch et al. also reported extremely low adherence rate (3\%) in 113 patients with colorectal cancer receiving MEC or LEC. ${ }^{17}$ The pattern of non-adherence to ASCO guidelines in our study included overuse of ondansetron before chemotherapy regimens classified as having low or minimal emetic risk. This was inconsistent with ASCO guidelines and indicates unnecessarily high cost. Also there was a lack of prescription of dexamethasone in 16 of 80 patients receiving HEC and MEC regimens. However, ASCO guidelines recommend the use of dexamethasone for the acute prevention of highly, moderately and low emetogenic chemotherapy. This finding may be attributed to physicians' perception of steroid-related adverse events. Similarly, underuse of dexamethasone was described in a previous study from Saudi Arabia. ${ }^{16}$ In $14 \%$ of patients in this study, dexamethasone was prescribed as antiemetic prophylaxis to patients already receiving prednisolone-containing chemotherapy. The steroid duplication was also described in a previous study. ${ }^{16}$ 
In this study, an oral 5-HT3 antagonist was prescribed to all patients at discharge, regardless of the emetogenicity of the chemotherapy. Overuse of 5-HT3 receptor antagonists was documented in a previous study in Brazil. ${ }^{18}$ Although continuing ondansetron alone beyond $24 \mathrm{~h}$ has a minor role in the control of delayed CINV in patients who received HEC, ${ }^{19}$ the benefit has not been as great as that seen with dexamethasone monotherapy. ${ }^{20}$ Furthermore, the addition of a 5-HT3 receptor antagonist beyond $24 \mathrm{~h}$ along with glucocorticoids did not significantly improve control of delayed emesis as compared with dexamethasone monotherapy. ${ }^{20}$ Thus, the use of 5 -HT3 receptor antagonists to prevent delayed emesis is not recommended. This finding suggests that there is overuse of an expensive antiemetic medication in a limited resource setting where there is an economic need for the reduction of medical care expenses.

ASCO guidelines suggest prophylactic administration of dexamethasone beyond $24 \mathrm{~h}$ after chemotherapy as part of triple therapy for HEC or as monotherapy for LEC. ${ }^{10}$ Our analysis revealed that no patient received dexamethasone on days 2 and 3 as prophylaxis for delayed emesis. The observed underuse of prophylactic dexamethasone for delayed CINV is similar to that found in previous studies. ${ }^{21}$ In this study, metoclopramide was prescribed as antiemetic prophylaxis for delayed emesis in $37 \%$ of patients, which was inconsistent with the recommendation of ASCO guidelines. Recent ASCO guidelines stated that metoclopramide should be reserved for patients who are intolerant to any of the 5-HT3 antagonists, dexamethasone or aprepitant.

The control of nausea was substantially lower than the control of vomiting in this study as shown in Table 4 . The data suggest that, whilst delayed nausea and vomiting were well controlled, acute nausea and vomiting remain a significant problem in practice. This is in contrast to some reports that have discussed the difficulty of prevention using antiemetic guidelines for delayed CINV. ${ }^{22}$ A previous survey showed underestimation of delayed CINV among medical oncologists and oncology nurses. ${ }^{23}$ Despite the use of prophylactic antiemetic medications, a study has shown that $36 \%$ patients developed acute CINV and approximately 59\% developed delayed CINV. ${ }^{24}$ Lack of NK-1-RA was a major obstacle in our patient group who were treated with HEC and MEC regimens and could have contributed to the poor outcome our patients experienced. Therefore, introduction of NK-1 receptor antagonists could improve compliance with treatment guidelines and improve patients' outcomes. Furthermore, proper utilisation of dexamethasone as recommended by ASCO guidelines could lead to greater control of CINV.

TABLE 4: Comparison of the CINV frequency in this study with previous studies.

\begin{tabular}{lccc}
\hline Characteristics & $\begin{array}{c}\text { Molassiotis et al. } .^{25} \\
\mathbf{( \% )}\end{array}$ & $\begin{array}{c}\text { Almazrou et al. } \\
\mathbf{( \% )}\end{array}$ & $\begin{array}{c}\text { This study } \\
\mathbf{( \% )}\end{array}$ \\
\hline Acute vomiting & 15.7 & 9.5 & 37 \\
Delayed vomiting & 14.7 & 8.4 & 12 \\
Acute nausea & 37.3 & 37.9 & 49 \\
Delayed nausea & 47.1 & 26.3 & 14 \\
\hline
\end{tabular}

Source: Almazrou \& Alnaim ${ }^{16}$ and Molassiotis et al ${ }^{25}$
To improve adherence to antiemetic guidelines at the NCI, the findings of this study were presented at the department scientific meetings and inadequate adherence to antiemetic guidelines was highlighted. Furthermore, departmental training sessions regarding appropriate use of the antiemetic guidelines were implanted.

\section{Conclusion}

We have conducted a prospective cross-sectional study to evaluate the patterns of prophylactic antiemetic use by patients with cancer during chemotherapy. Despite the availability of guidelines of antiemetic prophylaxis of CINV, this study indicated an extremely low adherence rate. Nonadherence included a trend of both underuse and overuse of indicated antiemetic medications.

\section{Acknowledgements Competing interests}

The authors declare that they have no financial or personal relationships that may have inappropriately influenced them in writing this article.

\section{Author(s) contributions}

M.M.A.E. was the project leader. A.A.S.A.A. was responsible for data collection. M.M.A.E., M.O.M.E. and A.A.S.A.A. contributed to project design and analysis and interpretation of data analysis and manuscript writing.

\section{References}

1. Lennard L. Therapeutic drug monitoring of antimetabolic cytotoxic drugs. $\mathrm{Br}$ Clin Pharmacol. 1999;47(2):131-143. http://dx.doi.org/10.1046/j.1365-2125. 1999.00884.x

2. Fernandez-Ortega $P$, Caloto MT, Chirveches $E$, et al. Chemotherapy-induced nausea and vomiting in clinical practice: Impact on patients' quality of life. Support Care Cancer. 2012;20(12):3141-3148. http://dx.doi.org/10.1007/ Support Care Cancer
s00520-012-1448-1

3. Hesketh PJ, Kris MG, Grunberg SM, et al. Proposal for classifying the acute emetogenicity of cancer chemotherapy. J Clin Oncol. 1997;15(1):103-109.

4. Hesketh PJ. Defining the emetogenicity of cancer chemotherapy regimens: Relevance to clinical practice. Oncologist. 1999;4(3):191-196.

5. Basch E, Prestrud AA, Hesketh PJ, et al. Antiemetics: American Society of Clinical Oncology clinical practice guideline update. J Clin Oncol. 2011;29(31):4189-4198. http://dx.doi.org/10.1200/JCO.2010.34.4614

6. Hesketh PJ. Comparative review of 5-HT3 receptor antagonists in the treatment of acute chemotherapy-induced nausea and vomiting. Cancer Invest. 2000; 18(2):163-173. http://dx.doi.org/10.3109/07357900009038248

7. Morran C, Smith DC, Anderson DA, McArdle CS. Incidence of nausea and vomiting with cytotoxic chemotherapy: A prospective randomised trial of antiemetics. Br Med J. 1979;1(6174):1323-1324. http://dx.doi.org/10.1136/ bmj.1.6174.1323-a

8. Gralla RJ, Osoba D, Kris MG, et al. Recommendations for the use of antiemetics: Evidence-based, clinical practice guidelines. American Society of Clinical Oncology. J Clin Oncol. 1999;17(9):2971-2994.

9. Affronti ML, Schneider SM, Herndon JE, 2nd, Schlundt S, Friedman HS. Adherence to antiemetic guidelines in patients with malignant glioma: A quality improvement project to translate evidence into practice. Support Care Cancer. 2014;22(7): 1897-1905. http://dx.doi.org/10.1007/s00520-014-2136-0

10. Hesketh PJ, Bohlke K, Lyman GH, et al. Antiemetics: American Society of Clinical Oncology Focused Guideline Update. J Clin Oncol. 2016;34(4):381-386. http:// dx.doi.org/10.1200/JCO.2015.64.3635

11. Roila F, Molassiotis A, Herrstedt J, et al. 2016 MASCC and ESMO guideline update for the prevention of chemotherapy- and radiotherapy-induced nausea and vomiting and of nausea and vomiting in advanced cancer patients. Ann Oncol. 2016;27(Suppl 5):v119-v133.

12. National Comprehensive Cancer N. NCCN antiemesis guidelines emphasize 'delayed' emesis, new 5-HT3 inhibitors, and NK-1 blockers. J Support Oncol. 2004;2(4):366. 
13. Aapro M, Molassiotis A, Dicato $M$, et al. The effect of guideline-consistent antiemetic therapy on chemotherapy-induced nausea and vomiting (CINV): The Pan European Emesis Registry (PEER). Ann Oncol. 2012;23(8):1986-1992. http:// Pan European Emesis Registry (PEER).
dx.doi.org/10.1093/annonc/mds021

14. Schwartzberg LS, Grunberg SM, Kris MG. Recent advances and updated guidelines in the management of chemotherapy-induced nausea and vomiting. Clin Adv Hematol Oncol. 2011;9(11 Suppl 27):1-14; quiz 5-6.

15. Zong X, Zhang J, Ji X, Gao J, Ji J. Patterns of antiemetic prophylaxis for chemotherapy-induced nausea and vomiting in China. Chin J Cancer Res. 2016;28(2):168-179. http://dx.doi.org/10.21147/j.issn.1000-9604.2016.02.04

16. Almazrou S, Alnaim L. Evaluation of adherence to chemotherapy-induced nausea and vomiting guidelines. An observational study. J Canc Ther. 2012;3:613-620. http://dx.doi.org/10.4236/jct.2012.35078

17. Koch S, Wein A, Siebler J, et al. Antiemetic prophylaxis and frequency of chemotherapy-induced nausea and vomiting in palliative first-line treatment of colorectal cancer patients: The Northern Bavarian IVOPAK I Project. Support Car Cancer. 2013;21(9):2395-2402. http://dx.doi.org/10.1007/s00520-013-1801-z

18. Franca MS, Uson Junior PL, Antunes YP, et al. Assessment of adherence to the guidelines for the management of nausea and vomiting induced by chemotherapy. Einstein (Sao Paulo). 2015;13(2):221-225. http://dx.doi. org/10.1590/S1679-45082015A03097

19. Olver I, Paska W, Depierre A, et al. A multicentre, double-blind study comparing placebo, ondansetron and ondansetron plus dexamethasone for the control of cisplatin-induced delayed emesis. Ondansetron Delayed Emesis Study Group. Ann Oncol. 1996;7(9):945-952. http://dx.doi.org/10.1093/oxfordjournals.annonc.a010798
20. Geling O, Eichler HG. Should 5-hydroxytryptamine-3 receptor antagonists be administered beyond 24 hours after chemotherapy to prevent delayed emesis? Systematic re-evaluation of clinical evidence and drug cost implications. I Clin Oncol. 2005;23(6):1289-1294. http://dx.doi.org/10.1200/ implications. J Clin

21. Fujii $\mathrm{H}$, lihara $\mathrm{H}$, Ishihara $\mathrm{M}$, Takahashi $\mathrm{T}$, Yoshida $\mathrm{K}$, Itoh $\mathrm{Y}$. Improvement of adherence to guidelines for antiemetic medication enhances emetic control in patients with colorectal cancer receiving chemotherapy of moderate emetic risk. Anticancer Res. 2013;33(12):5549-5556.

22. Jones JM, Qin R, Bardia A, Linquist B, Wolf $S$, Loprinzi CL. Antiemetics for chemotherapy-induced nausea and vomiting occurring despite prophylactic antiemetic therapy. J Palliat Med. 2011;14(7):810-814. http://dx.doi.org/10.1089/ jpm.2011.0058

23. Grunberg SM, Deuson RR, Mavros P, et al. Incidence of chemotherapy-induced nausea and emesis after modern antiemetics. Cancer. 2004;100(10):2261-2268. http://dx.doi.org/10.1002/cncr.20230

24. Cohen L, de Moor CA, Eisenberg P, Ming EE, Hu H. Chemotherapy-induced nausea and vomiting: Incidence and impact on patient quality of life at community oncology settings, Support Care Cancer, 2007:15(5):497-503. http://dx.doi. org/10.1007/s00520-006-0173-z

25. Molassiotis A, Saunders MP, Valle J, et al. A prospective observational study of chemotherapy-related nausea and vomiting in routine practice in a UK cancer centre. Support Care Cancer. 2008;16(2):201-208. http://dx.doi.org/10.1007/ s00520-007-0343-7 